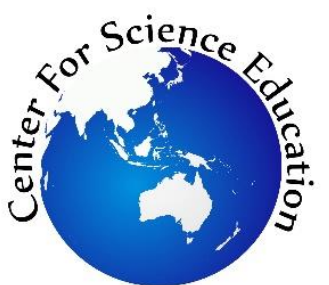

\author{
Tersedia online di EDUSAINS \\ Website: http://journal.uinjkt.ac.id/index.php/edusains
}

EDUSAINS, 12(2), 2020, 266-275

Research Artikel

EDUS:(1MP)

\title{
EKSPLORASI AKTIVITAS KEHIDUPAN SEHARI-HARI ANAK NELAYAN DI DESA LOBUK UNTUK MENDUKUNG PEMBELAJARAN IPA KONTEKSTUAL
}

\author{
EXPLORATION OF FISHERMAN CHILDREN'S DAILY LIFE ACTIVITIES AT LOBUK \\ VILLAGE TO SUPPORT CONTEXTUAL SCIENCE LEARNING
}

\author{
Novatul Labibah*, Herowati, Jefri Nur Hidayat, Habibi \\ Universitas Wiraraja, Indonesia \\ novapesisir2019@gmail.com
}

\begin{abstract}
The daily activities of fishermen's children can be used as a material context in applying contextual science learning, as emphasized by K13. In fact, learning science in coastal schools is not yet contextual to the daily activities of fishermen's children. This study aims to provide a description of the daily activities of fishermen's children in Lobuk Village, and a description of the relationship between these activities and science learning materials for SMP/MTs. This type of research is a descriptive qualitative case study method. The primary data sources were fishermen children aged SMP/MTs and their parents. Data collection techniques in the form of interviews, observation, and documentation. The results showed that fishermen's children's morning activities were helping with homework, preparing for school, then leaving for school. The daytime activity is helping the mother/aunt work in the drying process of the fish (a gherri jhuko'). The afternoon activity is looking for shells (arang-karang) during low tide, some of the shells are sold to earn pocket money or for parents, and some are used as salad. Nighttime activities are reciting/tarawih, tadarus, watching TV, then sleeping. The daily activities of fishermen children in their routine of helping to work a gherri jhuko' and arang-karang in Lobuk Village are related to science learning materials for SMP/MTs, namely the classification of shells in Mollusca type invertebrates; the application of solid substance pressure to the knife for nyetak, mowang bunto ', and a gherri jhuko'.
\end{abstract}

Keywords: activities; fisherman children; contextual learning

\begin{abstract}
Abstrak
Aktivitas sehari-hari anak nelayan bisa digunakan sebagai konteks materi dalam menerapkan pembelajaran IPA kontekstual, sebagaimana penekanan K13. Faktanya, pembelajaran IPA di sekolah pesisir belum kontekstual terhadap aktivitas sehari-hari anak nelayan. Penelitian ini bertujuan untuk memberikan deskripsi aktivitas sehari-hari anak nelayan di Desa Lobuk, dan deskripsi keterkaitan aktivitas tersebut dengan materi pembelajaran IPA SMP/MTs. Jenis penelitian ini adalah deskriptif kualitatif dengan metode studi kasus. Sumber data primer dari anak-anak nelayan usia SMP/MTs beserta orang tua. Teknik pengumpulan data berupa wawancara, observasi, dan dokumentasi. Hasil penelitian menunjukkan aktivitas pagi hari anak nelayan adalah membantu pekerjaan rumah, menyiapkan diri ke sekolah, lalu berangkat sekolah. Aktivitas siang hari adalah membantu ibu/bibinya bekerja dalam proses pengeringan ikan (a gherri jhuko'). Aktivitas sore hari adalah mencari kerang (arang-karang) saat air laut surut, sebagian kerang dijual untuk menghasilkan uang jajan atau untuk orang tua, dan sebagian lagi dirujak. Aktivitas malam hari adalah mengaji/tarawih, tadarus, nonton TV, lalu tidur. Aktivitas sehari-hari anak nelayan dalam rutinitas membantu bekerja a gherri jhuko' dan arangkarang di Desa Lobuk berkaitan dengan materi pembelajaran IPA SMP/MTs, yaitu pengklasifikasian kerang dalam avertebrata jenis Mollusca; penerapan tekanan zat padat pada pisau untuk nyetak, mowang bunto', dan a gherri jhuko'.
\end{abstract}

Kata Kunci: aktivitas; anak nelayan; pembelajaran kontekstual

Permalink/DOI: http:// doi.org/10.15408/es.v12i2.14938 


\section{PENDAHULUAN}

Permendikbud No. 22 Tahun 2016 tentang Standar Proses Pendidikan Dasar dan Menengah menyebutkan bahwa, Kurikulum 2013 (K13) menekankan aspek kontekstual dalam pembelajaran IPA (Baswedan, 2016; Habibi, 2016). Pembelajaran kontekstual adalah pendekatan pembelajaran melalui proses menghubungkan dan menerapkan materi pembelajaran dengan aktivitas sehari-hari siswa (Trianto, 2014).

Siswa dalam aktivitas sehari-hari memiliki pengetahuan awal untuk memahami materi pembelajaran IPA. Hal ini dibuktikan dengan peningkatan nilai siswa pada materi pembelajaran IPA kontekstual terhadap ekosistem pesisir mangrove di Kabupaten Sumenep (Habibi, 2016; Pramita, Mulyati \& Susanto, 2016; Sani, 2015; Trianto, 2014).

Kabupaten Sumenep di Kepulauan Madura memiliki potensi perikanan dan kelautan yang besar, sehingga mayoritas mata pencahariannya adalah nelayan (Sukandar et al., 2016). Aktivitas sehari-hari anak nelayan dapat dihubungkan dengan materi pembelajaran IPA, sehingga guru bisa menggunakannya sebagai konteks materi untuk menerapkan pembelajaran IPA kontekstual (Musfiqon \& Nurdyansyah, 2015).

Salah satu kebiasaan anak nelayan seharihari adalah rutinitas membantu pekerjaan orang tua untuk meningkatkan pendapatan ekonomi keluarga (Habibi, Anekawati \& Wati, 2012), sesuai dengan aktivitas anak nelayan di Desa Lobuk yang membantu pekerjaan orang tua dalam proses pengeringan ikan (a gherri jhuko') dan mencari kerang (arang-karang) (Wawancara; observasi dan dokumentasi, September 2018-Januari 2019). Kedua aktivitas ini berkaitan dengan materi pembelajaran IPA, yaitu tekanan zat padat berupa aktivitas a gherri jhuko' menggunakan pisau dan klasifikasi benda.

Keterkaitan aktivitas sehari-hari anak
nelayan dengan materi pembelajaran IPA
seharusnya berpotensi mendukung pembelajaran
IPA kontekstual. Kebiasaan anak nelayan
menggambarkan bagaimana dunia yang harus
dihadapi secara berulang setiap hari, sehingga

menurut Atkinson-Shiffrin (1968) akan membuat informasi masuk ke memori jangka panjang (Habibi, Anekawati \& Wati, 2012; Santrock, 2007). Faktanya, K13 berlaku di sekolah, namun proses pembelajaran IPA belum kontekstual terhadap aktivitas sehari-hari anak nelayan (Wawancara, Oktober 2018).

Cara mengajar guru IPA hanya menjelaskan materi pembelajaran dan contoh di buku paket, serta memberikan tugas yang tidak menuntut siswa menghubungkan materi pembelajaran IPA dengan aktivitas sehari-hari anak nelayan (Wawancara; angket; observasi; dan dokumentasi, September 2018-April 2019).

Guru IPA MTs Sunan Giri menyatakan bahwa, pembelajaran IPA belum kontekstual terhadap aktivitas sehari-hari anak nelayan. Guru hanya pernah menerapkan pembelajaran IPA kontekstual terhadap lingkungan secara umum (Wawancara; observasi; dan dokumentasi, Oktober 2018-April 2019).

Hambatan utama tidak menerapkan pembelajaran IPA kontekstual terhadap aktivitas sehari-hari anak nelayan adalah sulit mengeksplorasi kultur pesisir siswa, karena guru tidak berasal dari pesisir Lobuk (Wawancara dan dokumentasi, Oktober 2018), hal ini didukung dengan teori bahwa pembelajaran IPA SMP/MTs di pesisir Sumenep belum memperhatikan aspek kultur masyarakat karena guru yang berasal dari luar daerah pesisir sulit mengeksplorasi kultur siswanya (Habibi \& Anekawati, 2013).

Kondisi pembelajaran IPA yang tidak kontekstual akan membuat siswa tidak dapat menghubungkan materi pembelajaran IPA dengan pengetahuan awal dari aktivitas sehari-hari, sehingga pemahamannya tidak bermakna. Oleh karena itu, guru IPA perlu dibantu agar dapat menerapkan pembelajaran IPA kontekstual terhadap aktivitas sehari-hari anak nelayan.

Guru IPA bisa dibantu melalui penelitian kualitatif jenis studi kasus untuk mengeksplorasi aktivitas sehari-hari anak nelayan di Desa Lobuk. Selanjutnya, dianalisis materi pembelajaran IPA SMP/MTs dalam buku paket K13 revisi 2017-2018. Penelitian ini bertujuan untuk mendeskripsikan 
aktivitas sehari-hari anak nelayan di Desa Lobuk, dan keterkaitannya dengan materi pembelajaran IPA SMP/MTs. Luaran penelitian adalah buku narasi berisi materi pembelajaran IPA yang memuat eksplorasi kultur pesisir siswa untuk mendukung pembelajaran IPA kontekstual.

\section{METODE}

Jenis penelitian ini adalah deskriptif kualitatif dengan metode studi kasus, untuk mengeksplorasi secara deskriptif aktivitas sehari-hari anak nelayan di Desa Lobuk sesuai waktu (pagi-malam) yang telah ditentukan serta keterkaitannya dengan materi pembelajaran IPA SMP/MTs (Creswell, 2013). Penelitian ini dilaksanakan di Desa Lobuk Kecamatan Bluto Kabupaten Sumenep, selama 6 bulan yaitu Februari-Juli 2019. Subyek penelitian meliputi lima anak nelayan usia SMP/MTs beserta orang tua, dipilih dengan prosedur sampling purposif atas pertimbangan kesediaan dan kemampuan untuk menginformasikan aktivitas sehari-hari secara mendalam (Emzir, 2010).

Data aktivitas sehari-hari anak nelayan di Desa Lobuk dikumpulkan dengan teknik wawancara, observasi, dan dokumentasi (Sugiyono, 2013), menggunakan instrumen wawancara semiterstruktur dan lembar observasi partisipasi pasif (Sugiyono, 2014).

Data hasil penelitian dianalisis menggunakan Model Miles \& Huberman (Sugiyono, 2014) sebagai berikut:

\section{Data Reduction}

Data aktivitas sehari-hari anak nelayan dideskripsikan secara sistematis dengan merangkum catatan lapangan dan laporan hasil wawancara yang masih kompleks, serta memfokuskan pada aktivitas yang berkaitan dengan materi pembelajaran IPA SMP/MTs K13 revisi 2017-2018. Aktivitas dikategorikan menjadi 2 kode, yaitu aktivitas proses pengeringan ikan ( $a$ gherri jhuko') dan aktivitas mencari kerang (arangkarang).

\section{Data Display}

Data aktivitas sehari-hari anak nelayan akan disajikan bersama analisis keterkaitannya dengan materi pembelajaran IPA SMP/MTs K13 revisi 2017-2018, dalam bentuk buku narasi untuk mendukung pembelajaran IPA kontekstual.

\section{Conclusion Drawing/Verification}

Kesimpulan dibuat setiap pengumpulan data berlangsung. Peneliti menganalisa aktivitas seharihari anak nelayan di Desa Lobuk dan keterkaitannya dengan materi pembelajaran IPA SMP/MTs K13 Revisi 2017-2018 dalam bentuk kesimpulan yang tentatif, untuk diverifikasi seiring bertambahnya data, sehingga diperoleh kesimpulan akhir yang akurat. Uji kredibilitas data hasil penelitian (Sugiyono, 2013) meliputi:

\section{Triangulasi}

Triangulasi Sumber: Data hasil wawancara anak nelayan tentang aktivitas sehari-hari dicek melalui wawancara kepada orang tua (bapak dan ibu).

Triangulasi Teknik

Data wawancara aktivitas sehari-hari anak nelayan dicek menggunakan teknik observasi dan dokumentasi.

Menggunakan Bahan Referensi: Data hasil observasi didukung dengan foto yang menunjukkan kebenaran deskripsi aktivitas.

Diskusi dengan Teman Sejawat: Mendiskusikan hasil penelitian dengan teman sejawat yang memiliki penelitian yang sama (Moleong, 2014).

\section{HASIL DAN PEMBAHASAN}

Aktivitas pagi hari anak nelayan adalah membantu pekerjaan rumah (menyapu, mencuci alat dapur dan pakaian, memasak), menyiapkan diri ke sekolah (mandi, mengenakan seragam, sarapan), lalu berangkat sekolah.

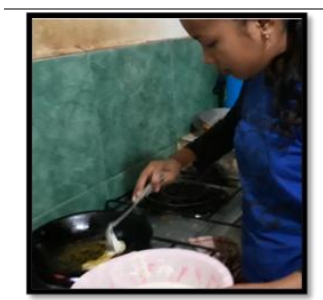

Gambar 1. Nor Memasak

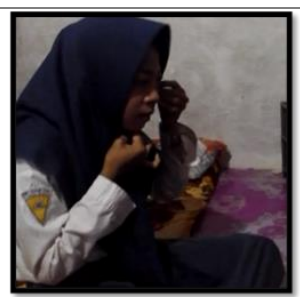

Gambar 2. Ina Siap-siap ke Sekolah 


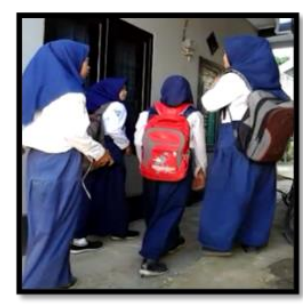

Gambar 3. Ise, Ifa, Ina dan Nisa Berangkat Sekolah

Aktivitas siang hari anak nelayan adalah membantu ibu/bibinya bekerja dalam proses pengeringan ikan (a gherri jhuko'), sehingga meningkatkan pendapatan ekonomi keluarga. Tahapan proses pengeringan ikan yang sering dibantu anak nelayan adalah memotong kepala (nyetak) dan ekor (mowang bunto') ikan, membelah dan membersihkan seluruh isi tubuh ikan (a gherri jhuko'), mencuci ikan, menata ikan di sanoko, menjemur ikan di bawah panas matahari, dan mengangkat jemuran ikan kering. Selebihnya, tahapan mengeluarkan persediaan ikan, menimbang ikan, mengasinkan ikan, dan mengemas ikan kering dikerjakan oleh ibu/orang dewasa di sekitarnya.

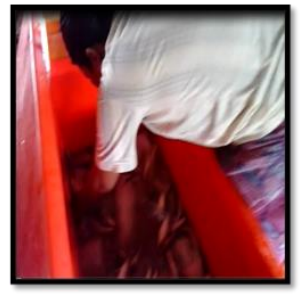

Gambar 4.

Mengeluarkan Ikan Bloso dari Box

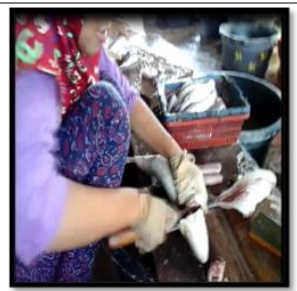

Gambar 6. Ifa

Memotong Kepala Ikan Bloso

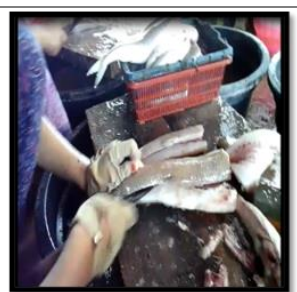

Gambar 8. Ifa a gherri Ikan Bloso

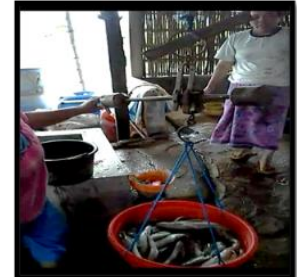

Gambar 5. Menimbang Massa Ikan Bloso

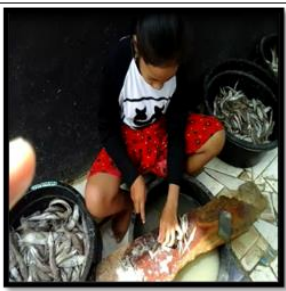

Gambar 7. Nor Memotong Ekor Ikan Co'o Pote

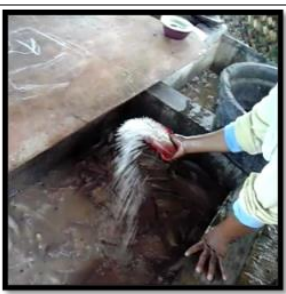

Gambar 9. Mencuci dan Mengasinkan Ikan Bloso

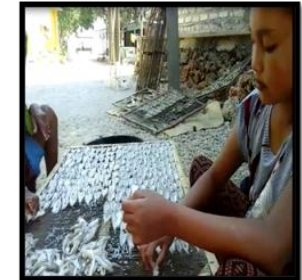

Gambar 10. Ise Menata

Ikan Janggala' ke Sanoko

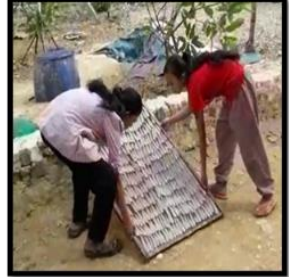

Gambar 11. Ina Menjemur Ikan Co'o Pote di Bawah Panas

Matahari

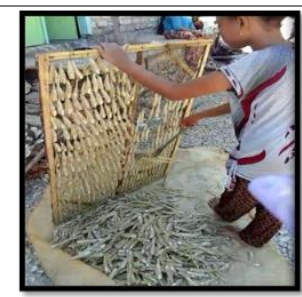

Gambar 12. Ise Mengangkat Jemuran Ikan Co'o Pote Kering

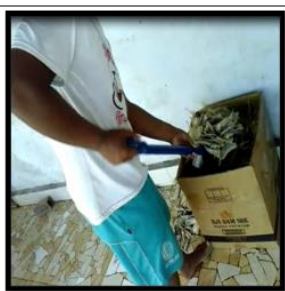

Gambar 13. Pengemasan Ikan Janggala' Kering

Aktivitas sore hari anak nelayan adalah mencari kerang (arang-karang) saat air laut surut (aēng asat). Mereka menggali pasir menggunakan sendok untuk arang-karang yang tertimbun pasir, serta berjalan sambil melihat ke bawah dan sekitarnya untuk arang-karang yang terdampar di permukaan pasir. Kerang yang diperoleh dijual untuk menghasilkan uang jajan sendiri. Ada juga yang uang hasil penjualan kerang diberikan kepada orang tua, sehingga dapat membantu memenuhi kebutuhan hidup keluarga. Sebagian kerang ada yang dimasak untuk dirujak bersama temantemannya.

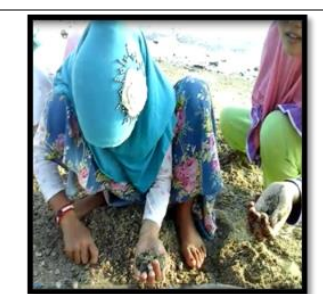

Gambar 14. Ise dan

Ifa Mencari Kerang yang Tertimbun Pasir

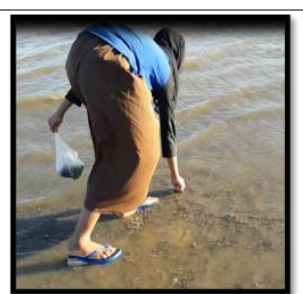

Gambar 15. Nor Mencari Kerang yang Terdampar di Permukaan Pasir 


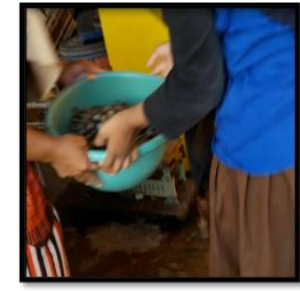

Gambar 16. Nor Menjual Kerang

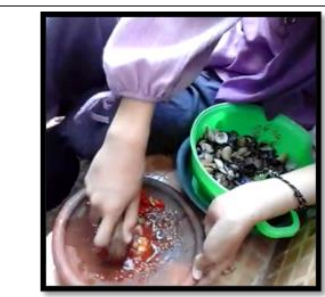

Gambar 18. Membuat Sambal

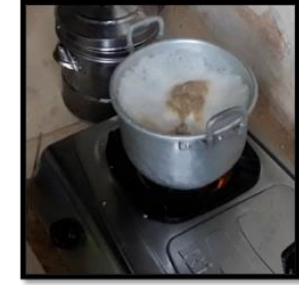

Gambar 17. Ina Merebus Kerang

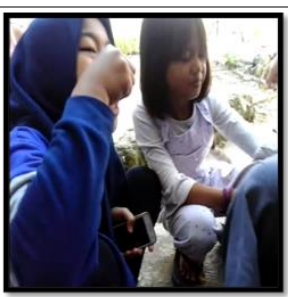

Gambar 19. Ifa Makan

Rujak Kerang
Aktivitas malam hari anak nelayan adalah mengaji/tarawih dan tadarus (khusus bulan puasa), nonton TV, lalu tidur.

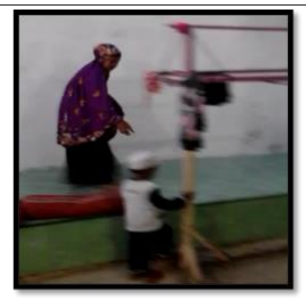

Gambar 20. Ise

Berangkat Mengaji

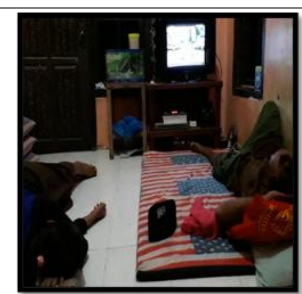

Gambar 21. Nor dan Bapaknya Nonton TV Sampai Tidur
Aktivitas sehari-hari anak nelayan tersebut menunjukkan rutinitas anak nelayan dalam membantu bekerja a gherri jhuko' dan arangkarang untuk meningkatkan pendapatan ekonomi keluarga. Hal ini didukung dengan penelitian lain yang menyatakan bahwa para nelayan memanfaatkan tenaga anak-anak mereka untuk membantu meningkatkan pendapatan dan mengurangi beban keluarga (Zain, Kamarudin \& Saad, 2018). Terdapat 50\% anak nelayan menyadari tekanan finansial orang tua, sehingga membantu bekerja atas inisiatifnya sendiri (Udoh, Achike \& Mkpado, 2013).

Dukungan teori tersebut diperkuat oleh penelitian yang menyatakan seluruh anggota keluarga nelayan, yaitu istri dan anak membantu bekerja untuk memenuhi kebutuhan hidup seharihari. Istri dan anak perempuan membantu bekerja mengelola atau menjual hasil tangkapan ikan, sedangkan anak laki-laki ikut melaut (Misbahudin, 2017). Selain itu, penelitian studi etnografi kondisi keseharian anak pesisir menghasilkan temuan, bahwa orang tua hanya memperhatikan proses belajar anak di rumah pada rutinitas belajar keterampilan kerja untuk membantu meringankan pekerjaan dan meningkatkan pendapatan keluarga seperti bertani garam, menangkap ikan (Habibi, Anekawati \& Wati, 2012).

Aktivitas sehari-hari anak nelayan dalam rutinitas membantu bekerja dalam proses pengeringan ikan (a gherri jhuko') dan mencari kerang (arang-karang) di Desa Lobuk berkaitan dengan materi pembelajaran IPA SMP/MTs, sebagaimana Tabel 1.

Tabel 1. Keterkaitan Aktivitas Sehari-hari Anak Nelayan dalam Rutinitas Membantu Bekerja A Gherri Jhuko' dan Arangkarang di Desa Lobuk dengan Materi Pembelajaran IPA SMP/MTs

\begin{tabular}{|c|c|c|c|c|}
\hline \multirow[t]{2}{*}{ No. } & \multirow{2}{*}{$\begin{array}{l}\text { Aktivitas } \\
\text { (Siang/Sore) }\end{array}$} & \multicolumn{3}{|c|}{ Materi Pembelajaran IPA } \\
\hline & & $\begin{array}{l}\text { Kelas/ } \\
\text { Semester }\end{array}$ & Bab & Materi Pokok \\
\hline 1. & $\begin{array}{l}\text { Menimbang massa ikan } \\
\text { (Siang) dan kerang (Sore) }\end{array}$ & VII/1 & $\begin{array}{l}\text { Bab } 1 \text { tentang objek IPA } \\
\text { dan pengamatannya }\end{array}$ & $\begin{array}{l}\text { Besaran pokok: massa ikan dan kerang adalah salah satu besaran } \\
\text { pokok, dalam SI massa diukur dalam satuan kilogram (kg) seperti } \\
\text { massa ikan bloso } 12 \mathrm{~kg} \text { dan massa kerang } 5 \mathrm{~kg} \text { (Widodo, } \\
\text { Rachmadiarti and Hidayati, 2017a). }\end{array}$ \\
\hline 2. & $\begin{array}{l}\text { Mengeringkan jenis ikan } \\
\text { capung (jhuko' co'o pote), } \\
\text { lar-olaran, janggala', dan } \\
\text { bloso (Siang) }\end{array}$ & VII/1 & $\begin{array}{l}\text { Bab } 2 \text { tentang klasifikasi } \\
\text { makhluk hidup }\end{array}$ & $\begin{array}{l}\text { Kelompok hewan bertulang belakang (vertebrata): jenis-jenis ikan } \\
\text { tersebut adalah contoh hewan vertebrata (Widodo, Rachmadiarti and } \\
\text { Hidayati, 2017a). }\end{array}$ \\
\hline 3. & $\begin{array}{l}\text { Menemukan kerang } \\
\text { cemmis, kerang manis, } \\
\text { kerang bulu, tiram } \\
\text { (terem), dan keong hisap } \\
\text { (cong-cong keccot) (Sore) }\end{array}$ & VII/1 & $\begin{array}{l}\text { Bab } 2 \text { tentang klasifikasi } \\
\text { makhluk hidup }\end{array}$ & $\begin{array}{l}\text { Kelompok hewan tidak bertulang belakang (avertebrata): contoh } \\
\text { hewan Mollusca adalah kerang cemmis, kerang manis, kerang bulu, } \\
\text { terem, dan cong-cong keccot (Widodo, Rachmadiarti and Hidayati, } \\
\text { 2017a). }\end{array}$ \\
\hline 4. & $\begin{array}{l}\text { Menemukan kepiting dan } \\
\text { beka'(Sore) }\end{array}$ & VIII/1 & $\begin{array}{l}\text { Bab } 2 \text { tentang klasifikasi } \\
\text { makhluk hidup }\end{array}$ & $\begin{array}{l}\text { Kelompok hewan tidak bertulang belakang (avertebrata): salah satu } \\
\text { kelas Arthropoda adalah Crustacea, contohnya kepiting dan beka } \\
\text { (Widodo, Rachmadiarti and Hidayati, 2017a). }\end{array}$ \\
\hline
\end{tabular}




\begin{tabular}{|c|c|c|c|}
\hline \multirow[t]{2}{*}{ No. } & \multirow{2}{*}{$\begin{array}{l}\text { Aktivitas } \\
\text { (Siang/Sore) }\end{array}$} & \multicolumn{2}{|c|}{ Materi Pembelajaran IPA } \\
\hline & & $\begin{array}{l}\text { Kelas/ } \\
\text { Semester }\end{array}$ & Bab \\
\hline 5. & $\begin{array}{l}\text { Memakan buah kaktus } \\
\text { (Prickly pears/Pir } \\
\text { berduri), dan spontanitas } \\
\text { mengeluarkan tangannya } \\
\text { dari kantong celana } \\
\text { karena tertusuk duri buah } \\
\text { kaktus (Sore) }\end{array}$ & $\mathrm{VII} / 1$ & $\begin{array}{l}\text { Bab } 2 \text { tentang klasifikasi } \\
\text { makhluk hidup }\end{array}$ \\
\hline 6. & $\begin{array}{l}\text { Mengeluarkan ikan bloso } \\
\text { dari box berisi es batu } \\
\text { yang telah mencair } \\
\text { (Siang) }\end{array}$ & $\mathrm{VII} / 1$ & $\begin{array}{l}\text { Bab } 3 \text { tentang klasifikasi } \\
\text { materi dan perubahannya }\end{array}$ \\
\hline 7. & $\begin{array}{l}\text { Membakar daun kelapa } \\
\text { kering } \\
\text { membersihkan tiram dari } \\
\text { dasar perahu (Sore) }\end{array}$ & $\mathrm{VII} / 1$ & $\begin{array}{l}\text { Bab } 3 \text { tentang klasifikasi } \\
\text { materi dan perubahannya }\end{array}$ \\
\hline 8. & Merebus kerang (Sore) & $\mathrm{VII} / 1$ & $\begin{array}{l}\text { Bab } 4 \text { tentang suhu dan } \\
\text { perubahannya }\end{array}$ \\
\hline 9. & $\begin{array}{l}\text { Menjemur ikan di bawah } \\
\text { panas matahari (Siang) }\end{array}$ & $\mathrm{VII} / 1$ & $\begin{array}{l}\text { Bab } 5 \text { tentang kalor dan } \\
\text { perpindahannya }\end{array}$ \\
\hline 10. & Merebus kerang (Sore) & $\mathrm{VII} / 1$ & $\begin{array}{l}\text { Bab } 5 \text { tentang kalor dan } \\
\text { perpindahannya }\end{array}$ \\
\hline
\end{tabular}
perpindahannya

\section{Materi Pokok}

Ciri-ciri makhluk hidup: menunjukkan ciri makhluk hidup yang ke-3 yaitu makan, dan ke-7 yaitu peka terhadap rangsang (Widodo, Rachmadiarti and Hidayati, 2017a).

Perubahan fisika: es batu dalam box pengawetan ikan bloso, baik sebelum atau setelah mencair memiliki komposisi yang sama yaitu $\mathrm{H}_{2} \mathrm{O}$ (Widodo, Rachmadiarti and Hidayati, 2017a).

Perubahan kimia: pembakaran daun kelapa kering yang ditandai oleh terbentuknya zat baru yaitu abu, terbentuknya gas karbondioksida, dan mengalirnya energi panas dari kobaran api ke tiram yang menempel kuat di kayu bagian dasar perahu (Widodo, Rachmadiarti and Hidayati, 2017a).

Pemuaian zat cair dan gas: peristiwa naiknya busa air rebusan kerang ke permukaan panci saat dipanaskan menunjukkan pemuaian volume zat cair, sedangkan turunnya busa tersebut ke permukaan kerang menunjukkan penyusutan volume zat cair karena panas mulai dilepaskan kembali ke lingkungan (Widodo, Rachmadiarti and Hidayati, 2017a).

Perpindahan kalor secara radiasi: terjadi pada proses pengeringan ikan melalui perpindahan panas dari matahari ke bumi saat ikan dijemur (Widodo, Rachmadiarti and Hidayati, 2017a).

Kalor pada perubahan wujud benda: kepulan asap putih dari panci perebusan kerang adalah gelembung uap air yang menunjukkan perubahan wujud dari air menjadi uap (gas). Perpindahan kalor:

a. Konduksi: terjadi pada perpindahan panas dari api melalui panci perebusan kerang berbahan aluminium. Selain itu, saringan serok peniris untuk mengaduk, mengambil, mengangkat, dan meniriskan kerang manis dari air rebusan yang masih panas memanfaatkan sifat konduktivitas bahan.

b. Konveksi: terjadi pada perpindahan panas dari panci aluminium ke air rebusan kerang membentuk arus konveksi (Widodo, Rachmadiarti and Hidayati, 2017a).

\begin{tabular}{llll}
\hline 11. & $\begin{array}{l}\text { Menemukan udang di } \\
\text { dalam tubuh ikan } \\
\text { janggala' dan lar-olaran } \\
\text { (Siang) }\end{array}$ & & $\begin{array}{l}\text { Bab 2 tentang interaksi } \\
\text { makhluk hidup dengan } \\
\text { lingkungan }\end{array}$ \\
\hline 12. & $\begin{array}{l}\text { Menemukan ikan kecil di } \\
\text { dalam cangkang tiram } \\
\text { (Sore) }\end{array}$ & VII/2 & $\begin{array}{l}\text { Bab 2 tentang interaksi } \\
\text { makhluk hidup dengan } \\
\text { lingkungan }\end{array}$ \\
\hline 13. & $\begin{array}{l}\text { Menemukan rumput laut } \\
\text { hijau (Sore) }\end{array}$ & VII/2 & $\begin{array}{l}\text { Bab 2 tentang interaksi } \\
\text { makhluk hidup dengan } \\
\text { lingkungan }\end{array}$ \\
\hline 14. & $\begin{array}{l}\text { Menemukan beberapa } \\
\text { komponen di lingkungan } \\
\text { laut (Sore) }\end{array}$ & & $\begin{array}{l}\text { Bab 2 tentang interaksi } \\
\text { makhluk hidup dengan } \\
\text { lingkungan }\end{array}$ \\
& & &
\end{tabular}

Interaksi antara makhluk hidup dengan makhluk hidup yang lain: Ikan janggala' dan lar-olaran yang memangsa udang adalah contoh predasi (Widodo, Rachmadiarti and Hidayati, 2017b).

Interaksi antara makhluk hidup dengan makhluk hidup yang lain: ikan kecil yang hidup bersama kelompok tiram adalah contoh simbiosis komensalisme (Widodo, Rachmadiarti and Hidayati, 2017b).

Peran organisme berdasarkan kemampuan menyusun makanan: rumput laut hijau berperan sebagai organisme autotrof di lingkungan laut (Widodo, Rachmadiarti and Hidayati, 2017b).

Pengertian lingkungan dan hal-hal yang ditemukan dalam suatu lingkungan: komponen biotik (kerang cemmis, kerang manis, kerang bulu, terem, cong-cong keccot, kepiting, beka', jhuko' ellon, pohon mangrove, bulung, pohon kaktus), dan komponen abiotik (batu karang, sampan dan galangannya, saleret, air laut, pasir, kerikil, ombak, angin, tembok pembatas daerah laut dan darat) (Widodo, Rachmadiarti and Hidayati, 2017b).

15. Membuang sampah dan limbah cair rumah tangga masyarakat pesisir ke laut $\mathrm{VII} / 2 \quad \mathrm{Bab} \quad 3$ tentang (kondisional)

Pencemaran air: faktor penyebab pencemaran air laut adalah limbah organik (cangkang telur, ranting, cangkang kerang, dedaunan, tempurung kelapa, dan berbagai bahan lainnya yang dapat diuraikan oleh mikroorganisme) dan limbah anorganik (kantong plastik, plastik kemasan makanan ringan/instan, sterofoam, pempes, sandal, karung, botol plastik, baskom nasi, kemasan kaleng, kertas minyak, kardus, dan bahan lainnya yang sulit diuraikan oleh mikroorganisme), serta bahan berbahaya dan beracun (kotoran manusia yang mengandung ammonia, dan air limbah rumah tangga yang sudah tampak hitam pekat (celpa) mengandung sisa detergen bekas mencuci pakaian, air sisa sabun/shampoo bekas mandi, atau air sabun bekas mencuci berbagai peralatan dapur) sehingga dapat menyebabkan makhluk hidup di laut mati karena kekurangan oksigen dan keracunan (Widodo, Rachmadiarti and Hidayati, 2017b).

\begin{tabular}{lllrl} 
16. & $\begin{array}{l}\text { Mencari kerang pada } \\
\text { waktu air laut surut (Sore) }\end{array}$ & VII/2 Bab 6 tentang tata surya & $\begin{array}{l}\text { Kondisi bulan: kondisi surutnya air laut yang dimanfaatkan oleh } \\
\text { anak-anak nelayan untuk arang-karang adalah jenis pasang perbani, } \\
\text { pada tanggal 10-18 dan 28-3 berdasarkan penanggalan islam (bulan } \\
\text { Madhura) (Surinati, 2007; Widodo, Rachmadiarti and Hidayati, }\end{array}$ \\
\hline
\end{tabular}




\begin{tabular}{|c|c|c|c|}
\hline \multirow[t]{2}{*}{ No. } & \multirow{2}{*}{$\begin{array}{l}\text { Aktivitas } \\
\text { (Siang/Sore) }\end{array}$} & \multicolumn{2}{|c|}{ Materi Pembelajaran IPA } \\
\hline & & $\begin{array}{l}\text { Kelas/ } \\
\text { Semester }\end{array}$ & Bab \\
\hline 17. & $\begin{array}{l}\text { Menarik dan mendorong } \\
\text { kardus kemasan ikan } \\
\text { bloso kering (Siang) }\end{array}$ & VIII/1 & $\begin{array}{lrr}\text { Bab 1 } & \text { tentang } & \text { gerak } \\
\text { benda } & \text { dan } & \text { makhluk } \\
\text { hidup } & \text { di } & \text { lingkungan } \\
\text { sekitar } & & \\
\end{array}$ \\
\hline 18. & $\begin{array}{lr}\text { Memasukkan } & \text { tumpukan } \\
\text { ikan janggala' } & \text { kering ke } \\
\text { dalam } & \text { kardus } \\
\text { menggunakan } & \text { sekop } \\
(\text { sero') (Siang) } & \\
\end{array}$ & $\mathrm{VIII} / 1$ & $\begin{array}{l}\text { Bab } 2 \text { tentang usaha dan } \\
\text { pesawat sederhana dalam } \\
\text { kehidupan sehari-hari }\end{array}$ \\
\hline 19. & $\begin{array}{l}\text { Menemukan galangan } \\
\text { perahu di tepi laut (Sore) }\end{array}$ & VIII/1 & $\begin{array}{l}\text { Bab } 2 \text { tentang usaha dan } \\
\text { pesawat sederhana dalam } \\
\text { kehidupan sehari-hari }\end{array}$ \\
\hline
\end{tabular}

Materi Pokok

2017b).

Gaya: gaya gesek selalu berlawanan arah dengan gaya yang diberikan pada benda, contohnya adalah gaya gesekan antara dasar kardus kemasan ikan bloso kering dengan lantai (Zubaidah, Mahanal, Yuliati, Dasna, Ardian A. Pangestuti, et al., 2017a).

Jenis-jenis pesawat sederhana: sero' adalah contoh pesawat sederhana yaitu alat pengungkit jenis ketiga (letak titik tumpu di bagian sekop, gaya kuasa di gagang besi bagian tengah, dan gaya beban di ujung atas gagang besi) (Zubaidah, Mahanal, Yuliati, Dasna, Ardian A. Pangestuti, et al., 2017a).

Jenis-jenis pesawat sederhana: contoh penerapan bidang miring adalah galangan perahu yang terbuat dari kayu datar, namun didesain membentuk bangun segitiga dan terpasang satu kayu datar lagi dari puncak ke arah kaki segitiga membentuk bangun bidang miring sehingga memperkecil gaya kuasa, oleh karena itu dasar perahu yang ditopang oleh bidang miring tidak merosot (Zubaidah, Mahanal, Yuliati, Dasna, Ardian A. Pangestuti, et al., 2017a).

\begin{tabular}{llll}
\hline 20. & Menemukan pohon & $\mathrm{VIII} / 1$ & \\
mangrove dengan akar & & Bab tentang struktur \\
dan fungsi tumbuhan
\end{tabular}

Struktur dan fungsi akar: akar pohon mangrove mengalami modifikasi sehingga dapat berfungsi untuk menyerap oksigen atau bernapas yaitu akar pasak, akar tunjang untuk menunjang agar batang mangrove tidak rebah bila dihempas angin dan bertahan dari deburan ombak (Zubaidah, Mahanal, Yuliati, Dasna, Ardian A. Pangestuti, et al., 2017a).

21. Menemukan rumput laut $\mathrm{VIII} / 1 \quad \mathrm{Bab} 3$ tentang struktur hijau (Sore) dan fungsi tumbuhan

Struktur dan fungsi daun: warna hijau pada rumput laut disebabkan karena mengandung zat warna hijau yang disebut klorofil sehingga dapat berfotosintesis (Zubaidah, Mahanal, Yuliati, Dasna, Ardian A. Pangestuti, et al., 2017a).

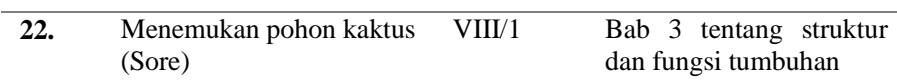

Struktur dan fungsi daun: tubuh kaktus yang pipih dan hijau adalah organ batang yang mengandung klorofil, sedangkan duri tajam yang tersebar di organ batang adalah bentuk modifikasi daun untuk menghemat air dari penguapan (Zubaidah, Mahanal, Yuliati, Dasna, Ardian A Pangestuti, et al., 2017).

\begin{tabular}{lllll}
\hline 23. & $\begin{array}{l}\text { Mengeluarkan ikan dari } \\
\text { pendinginan dalam box } \\
\text { (Siang) }\end{array}$ & VIII/1 & $\begin{array}{l}\text { Bab } 5 \text { tentang zat aditif } \\
\text { dan zat adiktif }\end{array}$ \\
\hline 24. & $\begin{array}{l}\text { Mengasinkan ikan bloso } \\
\text { (Siang) }\end{array}$ & VIII/1 & $\begin{array}{l}\text { Bab } 5 \text { tentang zat aditif } \\
\text { dan zat adiktif }\end{array}$ \\
\hline
\end{tabular}

Pengawet: pendinginan merupakan salah satu metode pengawetan ikan dengan cara fisik (Siburian, Dewi and Kariada, 2012; Zubaidah, Mahanal, Yuliati, Dasna, Ardian A. Pangestuti, et al., 2017a). Pengawet: pengasinan merupakan salah satu cara mengawetkan ikan menggunakan zat pengawet alami yaitu garam (bujhā) (Zubaidah, Mahanal, Yuliati, Dasna, Ardian A. Pangestuti, et al., 2017a; Puspita, Agustini and Purnamayati, 2019).

\begin{tabular}{llrll}
\hline 25. & $\begin{array}{l}\text { Mengeringkan } \\
\text { (Siang) }\end{array}$ & ikan & VIII/1 & $\begin{array}{l}\text { Bab 5 tentang zat aditif } \\
\text { dan zat adiktif }\end{array}$ \\
\hline 26. & $\begin{array}{l}\text { Menemukan } \\
\text { memakan buah kaktus } \\
\text { merah (Sore) }\end{array}$ & VIII/1 & $\begin{array}{l}\text { Bab 5 tentang zat aditif } \\
\text { dan zat adiktif }\end{array}$ \\
& & & \\
\hline 27. & $\begin{array}{l}\text { Membuat cengi bujha } \\
\text { cabbhi dan makan rujak } \\
\text { kerang (Sore) }\end{array}$ & & $\begin{array}{l}\text { Bab 5 tentang zat aditif } \\
\text { dan zat adiktif }\end{array}$ \\
& & &
\end{tabular}

Pengawet: pengeringan merupakan salah satu metode pengawetan ikan dengan cara fisik (Zubaidah, Mahanal, Yuliati, Dasna, Ardian A. Pangestuti, et al., 2017a).

Pewarna alami: salah satu buah yang dapat ditemukan di lingkungan pesisir sebagai bahan tambahan untuk memberikan warna merah pada makanan adalah buah kaktus (Zubaidah, Mahanal, Yuliati, Dasna, Ardian A. Pangestuti, et al., 2017a).

Penyedap: Bahan penyedap alami yang digunakan dalam sambal untuk meningkatkan cita rasa rujak kerang adalah garam (bujhā), cabai (cabbhi), dan kencur (kencor), sedangkan bahan penyedap buatannya adalah vetsin (micin) yang mengandung senyawa MSG (Zubaidah, Mahanal, Yuliati, Dasna, Ardian A. Pangestuti, et al., 2017a).

\begin{tabular}{|c|c|c|c|}
\hline 28. & $\begin{array}{l}\text { Mencuci ikan bloso asin } \\
\text { menggunakan campuran } \\
\text { air dan obat insektisida } \\
\text { Curacron 500EC (Siang) }\end{array}$ & VIII/1 & $\begin{array}{l}\text { Bab } 8 \text { tentang bahan } \\
\text { kimia dalam kehidupan }\end{array}$ \\
\hline 29. & $\begin{array}{l}\text { Nyetak, mowang bunto', } \\
\text { dan a gherri jhuko' } \\
\text { menggunakan pisau yang } \\
\text { tajam (Siang) }\end{array}$ & $\mathrm{VIII} / 2$ & $\begin{array}{l}\text { Bab } 7 \text { tentang tekanan } \\
\text { zat dan penerapannya } \\
\text { dalam kehidupan sehari- } \\
\text { hari }\end{array}$ \\
\hline 30. & $\begin{array}{l}\text { Menemukan fenomena } \\
\text { mengapungnya perahu } \\
\text { (sampan) dan kapal } \\
\text { (saleret) di permukaan air } \\
\text { laut (Sore) }\end{array}$ & VIII/2 & $\begin{array}{l}\text { Bab } 7 \text { tentang tekanan } \\
\text { zat dan penerapannya } \\
\text { dalam kehidupan sehari- } \\
\text { hari }\end{array}$ \\
\hline 31. & $\begin{array}{lr}\text { Menemukan tembok } \\
\text { pembatas daerah laut dan } \\
\text { darat yang semakin tebal } \\
\text { seiring rengan } \\
\text { bertambahnya } \\
\text { (Sore) }\end{array}$ & $\mathrm{VIII} / 2$ & $\begin{array}{l}\text { Bab } 7 \text { tentang tekanan } \\
\text { zat dan penerapannya } \\
\text { dalam kehidupan sehari- } \\
\text { hari }\end{array}$ \\
\hline
\end{tabular}
Pestisida: obat Curacron 500EC merupakan pestisida golongan insektisida untuk memberantas ulat agar tidak mengganggu ikan kering (Karim et al., 2008; Wariki, Siahaan and Rumondor, 2015; Sarwani, 2016).

Tekanan zat padat: penerapan tekanan zat padat $\left(\mathrm{p}=\bar{A}^{\frac{E}{A}}\right)$ pada pisau yang digunakan untuk nyetak, mowang bunto', dan a gherri jhuko' (Zubaidah, Mahanal, Yuliati, Dasna, Ardian A. Pangestuti, et al., 2017b).

Tekanan zat cair khususnya hukum Archimedes: gaya berat diperkecil oleh ruang yang berisi udara yaitu di lambung sampan dan saleret, tepatnya di bawah papan kayu (serap). $\rho$ udara tersebut lebih kecil daripada $\rho$ air laut, sehingga sampan dan saleret mendapatkan $F_{a}$ yang lebih besar daripada gaya beratnya (Zubaidah, Mahanal, Yuliati, Dasna, Ardian A. Pangestuti, et al., 2017b).

Tekanan zat cair khususnya tekanan hidrostatis: semakin ke bawah tembok pembatas dibuat lebih tebal, agar tidak jebol akibat terkena tekanan air laut yang semakin besar seiring dengan bertambahnya kedalaman (Zubaidah, Mahanal, Yuliati, Dasna, Ardian A. Pangestuti, et al., 2017b). 


\begin{tabular}{|c|c|c|c|c|}
\hline \multirow[t]{2}{*}{ No. } & \multirow{2}{*}{$\begin{array}{l}\text { Aktivitas } \\
\text { (Siang/Sore) }\end{array}$} & \multicolumn{3}{|c|}{ Materi Pembelajaran IPA } \\
\hline & & $\begin{array}{l}\text { Kelas/ } \\
\text { Semester }\end{array}$ & Bab & Materi Pokok \\
\hline 32. & $\begin{array}{l}\text { Menemukan gelombang } \\
\text { air laut (Sore) }\end{array}$ & $\mathrm{VIII} / 2$ & $\begin{array}{l}\text { Bab } 10 \text { tentang getaran, } \\
\text { gelombang, dan bunyi } \\
\text { dalam kehidupan sehari- } \\
\text { hari }\end{array}$ & $\begin{array}{l}\text { Gelombang: perambatan gelombang mekanis memerlukan medium, } \\
\text { misalnya gelombang air. Deburan ombak hanya memindahkan } \\
\text { sejumlah energi dengan memindahkan mediumnya (air laut) karena } \\
\text { angin sehingga terdengar suara ombak (energi gerak menjadi bunyi) } \\
\text { (Zubaidah, Mahanal, Yuliati, Dasna, Ardian A. Pangestuti, et al., } \\
\text { 2017b). }\end{array}$ \\
\hline
\end{tabular}

Keterkaitan aktivitas sehari-hari anak nelayan dengan materi pembelajaran IPA SMP/MTs di atas dapat mendukung pembelajaran IPA kontekstual. Hal ini sependapat dengan Habibi, Anekawati \& Wati (2012) bahwa kebiasaan seharihari anak Sumenep dalam membantu bekerja berpotensi mengembangkan pembelajaran IPA kontekstual. Kebiasaan anak menggambarkan dunia yang harus dihadapi setiap hari, sehingga pembelajaran berlandaskan kehidupan nyata ini membuat pemahaman siswa terhadap materi pembelajaran IPA akan lebih bermakna.

\section{PENUTUP}

Aktivitas pagi hari anak nelayan adalah membantu pekerjaan rumah, menyiapkan diri ke sekolah, lalu berangkat sekolah. Sepulang sekolah, membantu ibu/bibinya bekerja a gherri jhuko' pada siang hari, lalu arang-karang saat air laut surut pada sore hari. Sebagian kerang dijual untuk menghasilkan uang jajan atau untuk orang tua. Aktivitas malam harinya adalah mengaji/tarawih, tadarus, nonton TV, lalu tidur. Aktivitas sehari-hari anak nelayan dalam rutinitas membantu bekerja $a$ gherri jhuko' dan arang-karang di Desa Lobuk berkaitan dengan materi pembelajaran IPA SMP/MTs, yaitu pengklasifikasian kerang dalam avertebrata jenis Mollusca; penerapan tekanan zat padat pada pisau untuk nyetak, mowang bunto', serta a gherri jhuko'; dan sebagainya.

\section{DAFTAR PUSTAKA}

Baswedan, A. (2016) Peraturan Menteri Pendidikan dan Kebudayaan Republik Indonesia Nomor 22 Tahun 2016. Indonesia. Available at: https://luk.staff.ugm.ac.id/atur/bsnp/Permend ikbud22-2016SPDikdasmen.pdf.
Creswell, J. W. (2013) Research Design Pendekatan Kualitatif, Kuantitatif, dan Mixed. 3rd edn. Yogyakarta: Pustaka Pelajar.

Emzir (2010) Metodologi Penelitian Kualitatif Analisis Data. 2nd edn. Jakarta: Rajawali Pers.

Habibi (2016) 'Pengembangan Strategi Pembelajaran IPA Kontekstual Berbasis Ekosistem Mangrove', Jurnal Lentera Sains (Lensa), 6(November), pp. 69-75. Available at:

https://ejournalwiraraja.com/index.php/FKIP /article/view/288/246.

Habibi and Anekawati, A. (2013) 'Pengembangan Lembar Catatan Keluarga (LCK) untuk Mendukung Pembelajaran IPA SMP/MTs Berbasis Kultur Masyarakat Pesisir', Jurnal Lentera Sains (Lensa), 3, pp. 39-46.

Habibi, Anekawati, A. and Wati, H. D. (2012) Pembelajaran IPA Berbasis Kultur Masyarakat. Sumenep: Unija press.

Karim, S. et al. (2008) Belajar IPA: Membuka Cakrawala Alam Sekitar untuk Kelas VIII Sekolah Menengah Pertama/Madrasah Tsanawiyah. Edited by T. E. P. S. P. Inves. Jakarta: Pusat Perbukuan Departemen Pendidikan Nasional.

Misbahudin (2017) 'Persepsi Masyarakat Pesisir Pantai Utara Jawa Terhadap Pentingnya Pendidikan Formal sebagai Salah Satu Cara Meningkatkan Status Sosial di Masyarakat', Skripsi, pp. 1-134. Available at: http://repository.uinjkt.ac.id/dspace/bitstrea m/123456789/35346/2/MISBAHUDINFITK.pdf.

Moleong, L. J. (2014) Metodologi Penelitian Kualitatif. Bandung: Remaja Rosdakarya. 
Musfiqon, H. and Nurdyansyah (2015) Pendekatan Pembelajaran Saintifik. Pertama. Sidoarjo: Nizamia Learning Center Sidoarjo. Available at: http://eprints.umsida.ac.id/306/1/Buku Saintifik.pdf.

Pramita, M., Mulyati, S. and Susanto, H. (2016) 'Implementasi Desain Pembelajaran pada Kurikulum 2013 dengan Pendekatan Kontekstual', Jurnal Pendidikan: Teori, Penelitian, dan Pengembangan, 1(3), p. 289-296. doi: 10.17977/jp.v1i3.6150.

Puspita, D. A., Agustini, T. W. and Purnamayati, L. (2019) 'Pengaruh Perbedaan Konsentrasi Garam terhadap Kadar Asam Glutamat Pada Bubuk Bekasam Ikan Lele (Clarias batracus)', Jurnal Teknologi Pangan, 3(1), pp. 110-115.

Sani, R. A. (2015) Inovasi Pembelajaran. 2nd edn. Edited by Y. S. Hayati. Jakarta: PT Bumi Aksara.

Santrock, J. W. (2007) Psikologi Pendidikan. 2nd edn. Jakarta: Kencana Prenada Media Group.

Sarwani, M. (2016) Pestisida Pertanian dan Kehutanan Tahun 2016, Direktorat Pupuk dan Pestisida. Indonesia. Available at: http://psp.pertanian.go.id/assets/file/2016/Pe stisida Pertanian dan Kehutanan Tahun 2016.pdf.

Siburian, E. T. P., Dewi, P. and Kariada, N. (2012) 'Pengaruh Suhu dan Waktu Penyimpanan Terhadap Pertumbuhan Bakteri dan Fungi Ikan Bandeng', Unnes Journal of Life Science, 1(2), pp. 101-105. Available at: http://journal.unnes.ac.id/sju/index.php/Unne sJLifeSci.

Sugiyono (2013) Metode Penelitian Kombinasi (Mixed Methods). 4th edn. Edited by Sutopo. Bandung: Alfabeta.

Sugiyono (2014) Memahami Penelitian Kualitatif. 9th edn. Bandung: Alfabeta.

Sukandar et al. (2016) Profil Desa Pesisir Provinsi Jawa Timur Volume 3 (Kepulauan Madura). Surabaya: Bidang Kelautan, Pesisir, dan
Pengawasan Dinas Perikanan dan Kelautan Provinsi Jawa Timur. Available at: http://bpp.fpik.ub.ac.id/wpcontent/uploads/2017/02/profil-desa-pesisirkep.-madura-Vol-3.pdf.

Surinati, D. (2007) 'Pasang Surut dan Energinya', in Oseana. Jakarta: Pusat Penelitian Oseanografi-LIPI, pp. 15-22. doi: 10.1109/ICHI.2018.00101.

Trianto (2014) Mendesain Model Pembelajaran Inovatif, Progresif, dan Kontekstual. Jakarta: Prenada Media Group.

Udoh, M. T., Achike, A. I. and Mkpado, M. (2013) 'Effects of Fishing Activities on the Academic Performance of Teenagers in Riverine Areas of Nigeria: Implications for Educational Development Policy in Nigeria', Journal of Studies in Social Sciences, 2(2), pp. 211-227. Available at: https://infinitypress.info/index.php/jsss/articl e/download/76/71.

Wariki, W. C., Siahaan, R. and Rumondor, M. (2015) 'Analisis Kualitatif Residu Pestisida Profenofos Pada Tanaman Tomat di Kecamatan Langowan Barat Sulawesi Utara', Jurnal Ilmiah Sains, 15(1), pp. 4851. doi: 10.35799/jis.15.1.2015.8234.

Widodo, W., Rachmadiarti, F. and Hidayati, S. N. (2017) Buku Siswa Ilmu Pengetahuan Alam SMP/MTs Kelas VII Semester 1. 2017th edn. Jakarta: Kementerian Pendidikan dan Kebudayaan.

Widodo, W., Rachmadiarti, F. and Hidayati, S. N. (2017) Buku Siswa Ilmu Pengetahuan Alam SMP/MTs Kelas VII Semester 2. 2017th edn. Jakarta: Kementerian Pendidikan dan Kebudayaan.

Zain, R. M., Kamarudin, M. K. A. and Saad, M. H. MD. (2018) 'Assessment of Quality of Life on Fishermen Community in Kuala Terengganu, Malaysia: A Review', International Journal of Academic Research in Business and Social Sciences, 8(10), pp. 640-650. doi: 10.6007/IJARBSS/v8i10/4770. 
Zubaidah, S. et al. (2017) Buku Guru Ilmu Pengetahuan Alam SMP/MTs Kelas VIII. 2017th edn. Jakarta: Pusat Kurikulum dan Perbukuan, Balitbang, Kemendikbud. Available at: https://www.scribd.com/document/35788867 7/Buku-Guru-Kelas-8-IPA-pdf.

Zubaidah, S., Mahanal, S., Yuliati, L., Dasna, I. W., Pangestuti, A. A., et al. (2017) Buku
Siswa Ilmu Pengetahuan Alam SMP/MTs Kelas VIII Semester 1. 2017th edn. Jakarta: Kementerian Pendidikan dan Kebudayaan.

Zubaidah, S., Mahanal, S., Yuliati, L., Dasna, I. W., Pangestuti, A. A., et al. (2017) Buku Siswa Ilmu Pengetahuan Alam SMP/MTs Kelas VIII Semester 2. 2017th edn. Jakarta: Kementerian Pendidikan dan Kebudayaan 